\title{
A Markovian measure for evaluating accessibility to urban opportunities
}

\author{
Alireza Sahebgharani \\ Dept. of Architecture and Urban Planning \\ Art University of Isfahan \\ Isfahan, Iran \\ sahebgharani.alireza@gmail.com \\ Mahmoud Mohammadi \\ Dept. of Architecture and Urban Planning \\ Art University of Isfahan \\ Isfahan, Iran \\ m.mohammadi@aui.ac.ir
}

\author{
Hossein Haghshenas \\ Dept. of Transportation Engineering \\ Isfahan University of Technology \\ Isfahan, Iran \\ ho_hagh@cc.iut.ac.ir
}

Abstract: Accessibility is a fundamental notion in urban planning and its related fields. While accessibility is dynamic and varies during different time moments, most of the accessibility metrics are static and do not take this variation into account. In doing so, to address the questions of (1) how accessible urban opportunities are in different time moments and (2) how accessibility value of a person to a certain place changes regarding his/her spatiotemporal restrictions in time instants, this article-by using semi-Markovian and Brownian Bridge stochastic processes_offers a probabilistic time-dependent accessibility model that blends the magnitude of opportunities magnitude with the probability of individuals visiting.

To show the model's applicability, it was applied on a hypothetical case, along with two common accessibility metrics, and the outputs were compared. Then the proposed model was implemented in a study area for measuring temporal accessibility in two real policies made for daily markets in Isfahan, Iran. The first policy that presented the model application for analytical purposes was "market exclusion and area expansion," and the second policy that depicted the model implementation for normative usage was "new market location."

Results of the model execution on the hypothetical cases indicated there was a significant difference between the outputs of the common metrics and the ones of the proposed model. In addition, in the study area, the first policy generated higher total accessibility value in comparison with the second policy when market 2 was excluded and the area for market 8 was doubled.

Keywords: Accessibility, time geography, visiting probability, spacetime prism.

\section{Article history:}

Received: April 22, 2018

Received in revised form:

August 12, 2018

Accepted: September 23, 2018

Available online: January 28,

2018

Copyright 2019 Alireza Sahebgharani, Hossein Haghshenas \& Mahmoud Mohammadi http://dx.doi.org/10.5198/jtlu.2019.1408

ISSN: 1938-7849 | Licensed under the Creative Commons Attribution - Noncommercial License 4.0

The Journal of Transport and Land Use is the official journal of the World Society for Transport and Land Use (WSTLUR) and is published and sponsored by the University of Minnesota Center for Transportation Studies. 


\section{Introduction}

Understanding how people move and how they can access to the opportunities is necessary for comprehending the function of human settlements and providing livable places (Tenkanen, 2017). In this way, study of moving objects has become a noteworthy area of research in transportation and GISience (Laube, Imfeld, \& Weibel, 2005; Li, Zhang, Wang, \& Zeng, 2011). Time geography is a pivotal concept, both theoretically and practically, in these scientific scopes and is established around the notion of space-time prisms (STPs) that provides analytical tools for binding temporal aspects and location-based urban constructs such as accessibility. Classical STPs, demarcating reachable locations by a moving object given its origin, destination, and travel time budget, assume that all places within the boundary of a STP are equally accessible. This presumption neglects the interior properties of STPs as well as the fact that the probability of being in different locations inside a STP is not equal (Song \& Miller, 2014; Song, Miller, Zhou, \& Proffitt, 2016).

To differentiate locations within the prisms, recent studies have attempted to develop probabilistic models (Downs \& Horner, 2012; Horner \& Downs, 2014; Neutens, Schwanen, Witlox, \& De Maeyer, 2012; Song \& Miller, 2014; Song, et al., 2016; Winter \& Yin, 2010, 2011). A group of studies has revolved around the statistical time geographic constructs. Downs (2010) integrated kernel density estimation (see: (Xie \& Yan, 2008)) within STPs and proposed a time-geographic density estimation (TGDE) to identify probable locations of objects having the time budget between two benchmark points. Downs and Horner (2012) proffered a network-based TGDE which was able to produce potential path trees by using data gathered for vehicle's movement. Another group of research applied movement principles to estimate the visiting probability of mobile objects within STPs. Using Random Walk (RW) theory, Winter and Yin (2011) elaborated a mathematical framework to distinguish locations of an object, on the basis of the movement probability. Following the works of Winter and Yin, (2010, 2011), Song and Miller (2014) established models compatible with discrete and continuous times for simulating visiting probability in planar STPs. Song et al. (2016) moved the previous research forward adapting Brownian Bridge (BB) and semi-Markovian (SM) stochastic processes for modeling the probability of non-vehicular and vehicular movements within network-based space-time prisms (NTPs), respectively.

As accessibility is closely related to time geography, in that temporal features affect where and when individuals participate in activities and how transportation systems work (Tenkanen, 2017), recently, several measures have been developed for calculation of accessibility, applying space-time models (Church \& Marston, 2003; Delafontaine, Neutens, Schwanen, \& Van de Weghe, 2011; El-Geneidy \& Levinson, 2006; Ettema \& Timmermans, 2007; Kim \& Kwan, 2003; Kwan, Murray, O'Kelly, \& Tiefelsdorf, 2003; Kwan, 1998; Miller, 1999; Miller \& Wu, 2000; Neutens, Schwanen, Witlox, \& De Maeyer, 2010; O'Sullivan, Morrison, \& Shearer, 2000). Despite the variety of modeling approaches, these models can be generally classified in two categories: individual- and opportunity-based measures (Chen et al., 2016; Miller, 2007). While in opportunity-based measures accessibility value relates to activity places, in individual-based models, accessibility is calculated by considering spatial and personal restrictions. Measures in the first category are simple, easy to use, and aggregate but measures in the second category are disaggregate, representing time and space characteristics in details. However, individual-based measures commonly enlist deterministic STPs, they do not support the dynamics underlying accessibility changes, and cause accessibility value to be overestimated (Song et al. 2016).

In addition to the main classes of the accessibility models, another group of metrics, called blended measures, can be identified. These models attempt to put both person- and place-based approaches together for representing characteristics of these perspectives in a unified structure. For example, Downs and Horner (2012) combined a statistical function that estimates location of an individual on a road network with attractiveness of opportunities reachable in a given time window. However, despite the 
necessity of more investigations in this scope of research (Horner \& Downs, 2014), a dynamic probabilistic accessibility model incorporating movement principles along with characteristics of urban opportunities has not yet been elaborated and applied in practice. Therefore, this paper, that is an extension to the work of Song et al. (2016), aims to offer an accessibility model linking attractiveness of opportunities to transportation system by using BB and SM processes for tackling the following questions: (1) on the opportunity side, how accessible are urban opportunities in different moments of time? (or how accessibility of an opportunity has been changed during a time section?), and (2) on the individual side, how much is the accessibility of a person to a certain place regarding his/her spatiotemporal restriction and attendance probability in time instants? To apply the proposed measure and show its analytical and practical implications, two policies made by municipality of Isfahan in response to the issue of improving service delivery to the citizens by daily markets are considered. The first, "market exclusion and area expansion", is an application for analytical purpose and the second, "new market location", is an example of normative usage.

The rest of this paper is organized as follows. Section 2 outlines the background and concepts leading this research. Section 3 presents the model development process and analysis. Section 4 shows model implementation in the study area and results. Ultimately, the conclusions and further works are given in Section 5.

\section{Background and concepts}

\subsection{Time geography}

The notion of time geography, created by Hägerstraand (1970) and then operationalized by Lenntorp (1977), was established to describe activity pattern of individuals by capturing the spatiotemporal facets and the constraints imposed on a person by transportation and activity systems (Cerdá, 2009). These constraints are: (1) capability constraints which encompass physical and psychological requirements to engage in an activity; (2) coupling constraints which enfold spatiotemporal requirements that makes it possible to participate in different activities with other people; and (3) authority constraints which include laws that limit an individual's access to opportunities (Malekzadeh, 2015; Miller, 2007).

Time geography is constituted around the central concept of STP in which if origin and destination, available time for movement, and maximum moving speeds from an origin to a destination are given, STP will delimit all reachable locations and will determine the remaining available time to spend at each opportunity (Kwan \& Weber, 2008; Miller, 1991, 1999; Miller \& Bridwell, 2009; Song \& Miller, 2014). By iterating the calculation of STP for a number of individuals, their choice set and movement pattern can be tracked (Horner \& Downs, 2014). There are two classes of STPs: (1) punctiform prism which works on the basis of the opportunities Euclidian distance between origin and destination (see: (Miller, 1999; Song, 2015)), and (2) NTP that is congruent with the topology of the road network (Kim \& Kwan, 2003). STPs have been applied for studying various topics related to transportation by modeling both the physical social interaction (Farber, Neutens, Miller, \& Li, 2013) and the virtual one (Yu \& Shaw, 2008) to formation of travelers' choice set (Chen \& Kwan, 2012) to elaboration of mobility system (Winter $\&$ Raubal, 2006) and computation of accessibility as space-time concepts are appropriate for describing accessibility in the individual level (Malekzadeh, 2015; Song, 2015).

\subsection{Accessibility models}

Accessibility is a key concept in urban planning, transportation geography, and the other related fields. This notion is a multi-dimensional construct including individual, temporal, network, and land-use components (Geurs \& Ritsema van Eck, 2001; Geurs \& Van Wee, 2004). There is a wide variety of interpretations of accessibility from the opportunity attractiveness (Hansen, 1959) to the connectivity 
level of different locations (Ingram, 1971), to the ease of a place to be reached by different individuals in a certain geographical area (Cascetta, Cartenì, \& Montanino, 2013). However, after the paradigm shift from mobility to accessibility and by emerging sustainable transportation theories, this term is often defined as the ease of participating in different activities (Banister, 2008; Ferreira, Beukers, \& Te Brömmelstroet, 2012; Handy, 2002; Song, 2015). There are two main branches of accessibility models in the literature: opportunity- and individual-based measures.

Opportunity-based measures compute accessibility at a given location (Li et al., 2011). Distancebased (Geurs \& Van Wee, 2004), cumulative-based (Breheny, 1978; Envall, 2007), gravity-based (Hanson \& Schwab, 1987; Knox, 1978; Makri \& Folkesson, 1999; Shen, 1998), and place-rank models (El-Geneidy \& Levinson, 2006) are of the main categories of the opportunity-based measures. Although these models are simple in application and can be used to evaluate the impact of policy-related changes on the transportation or land-use system, these measures do not take individual preferences and spatiotemporal constraints into account, and are aggregate in nature (Chen et al., 2016; El-Geneidy \& Levinson, 2006; Miller, 2007).

Individual-based measures, in contrast to opportunity-based metrics, make one able to consider movement constraints and other factors related to travel-activity system (Horner \& Downs, 2014; Neutens et al., 2010). While individual-based measures connect all components of accessibility to each other (Geurs \& Van Wee, 2004), these measures need high-resolution data, and aggregation of their results together with relating person-level outputs to locations still remains a demanding scope for further research (Delafontaine, Neutens, \& Van de Weghe, 2012; Horner \& Downs, 2014; Neutens, Schwanen, \& Witlox, 2011).

\subsection{Related works}

Several studies have been dedicated to combining time geography with accessibility measurement. According to Lenntorp (1977) and Burns (1979), Miller (1991) and Miller and Wu (2000) developed a computational process to operationalize STPs for calculating accessibility value in real study areas. Kwan (1998) conducted a study to compare person-based metrics with place-based ones. She found that the results of these measures are widely different from each other. In line with these works, Neutens et al. (2010) did a comprehensive study including a large set of measures and analytically compared the outputs. They indicated that using different metrics makes different insights into the accessibility and service delivery analysis. It must be noted that in the aforementioned and other related papers, the accessibility of a person to opportunities distributed between two anchors pointing mandatory activities is computed (Delafontaine et al., 2012; Kim \& Kwan, 2003; Miller \& Wu, 2000) and the models can be applied to assess accessibility in the case of simulating potential trips, whether travel data is available or not.

In addition to the above mentioned studies, sporadic progresses were made on blending peopleand place-based models. Based on the perspective of statistical time geography, Horner and Downs (2014) enlisted network-based TGDE developed by Downs and Horner (2012) and applied it to identify links with more traversing probability and combined the attending probability with the opportunities attractiveness located along the network as a measure of accessibility. Similar to STP-based models, their metric can be applied in retrospective and prospective ways. In the same vein, some works modeled visiting probability of each segment of a street network by using movement principles. Following Song and Miller (2014) and Winter and Yin (2010,2011), Song et al. (2016) established a robust model to determine the probability of each link by BB and SM processes. Although this model shows the links more likely to be passed by a mobile object, it does not differentiate more probable opportunities to be visited and it is not applied to develop blended accessibility measures. The next section shows a blended probabilistic accessibility measure in coincidence with the movement principles. 


\section{Model development and analysis}

Recent work by Song et al. (2016) proposed models, on the basis of BB and SM stochastic processes, respectively for non-vehicular and vehicular moving objects in the street network. These models are applied to quantify visiting probability of edges and the most probable ones in the context of a street network. These probabilities are computed by the below equations (equation 1 -equation 6 ):

$$
\begin{aligned}
& P\left(e_{i j}, t\right)^{\text {non-vehicular }}=\frac{\sum_{a=i, j ; b=i, j} P_{a b}^{\text {non-vehicular }}(t)}{\sum_{e_{m n} \in E} P\left(e_{m n}, t\right)}, P_{i j}^{\text {non-vehicular }}(t) \\
& =\left\{\begin{array}{cc}
\varphi\left(\left(t_{i}^{-}\right)\right) \times \varphi\left(\left(t_{j}^{+}\right)\right) & t_{i}^{-}+t_{i j} \leq t_{j}^{+} \\
0 & \text { otherwise }
\end{array}\right. \\
& \varphi\left(t_{i}^{-}\right)=\left\{\begin{array}{cc}
0 & t_{i}^{-}>t \\
\frac{1}{\sqrt{2 \pi} \times \sigma \times\left(t-t_{o}\right)} \times e^{-\frac{\left(t_{i}^{-}-t_{o}\right)^{2}}{2 \sigma^{2}\left(t_{i}^{-}-t_{o}\right)^{2}}} & t_{i}^{-} \leq t
\end{array}\right. \\
& \varphi\left(t_{j}^{+}\right)=\left\{\begin{array}{cc}
0 & t_{j}^{+}>t \\
\frac{1}{\sqrt{2 \pi} \times \sigma \times\left(t_{D}-t\right)} \times e^{-\frac{\left(t_{D}-t_{j}^{+}\right)^{2}}{2 \sigma^{2}\left(t_{D}-t_{j}^{+}\right)^{2}}} & t_{j}^{+} \leq t
\end{array}\right. \\
& P\left(e_{i j}, t\right)^{\text {vehicular }}=\frac{\sum_{a=i, j ; b=i, j ; a \neq b} \text { pehicular }_{a b}(t)}{\sum_{e_{m n} \in E} P\left(e_{m n}, t\right)}, P_{i j}^{\text {vehicular }}(t)=\left\{\begin{array}{cc}
P_{0 \rightarrow i}(t) \times P_{j \rightarrow D}(t) & \text { if } e_{i j} \in E \text { and } t_{i}^{-}+t_{i j} \leq t_{j}^{+} \\
0 & \text { otherwise }
\end{array}\right. \\
& P_{O \rightarrow i}(t)=\left\{\begin{array}{cc}
0 & t \in\left[t_{o}, t_{i}^{-}\right) \\
\int_{t_{i}^{-}}^{t} \lambda e^{-\lambda \tau} d \tau=e^{-\lambda t_{i}^{-}}-e^{-\lambda t} & t \in\left[t_{i}^{-}, t_{i}^{+}-t_{i j}\right) \\
\int_{t_{i}^{-}}^{t_{j}^{+}-t_{i j}} \lambda e^{-\lambda \tau} d \tau=e^{-\lambda t_{i}^{-}}-e^{-\lambda\left(t_{j}^{+}-t_{i j}\right)} & t \in\left[t_{i}^{+}-t_{i j}, t_{D}\right]
\end{array}\right. \\
& P_{j \rightarrow D}(t)=\left\{\begin{array}{cc}
0 & t \in\left[t_{j}^{+}, t_{D}\right) \\
\int_{t_{D}-t_{j}^{+}}^{t_{D}-t} \lambda e^{-\lambda \tau} d \tau=e^{-\lambda\left(t_{D}-t_{j}^{+}\right)}-e^{-\lambda\left(t_{D}-t\right)} & t \in\left[t_{i}^{-}-t_{i j}, t_{j}^{+}\right) \\
\int_{t_{D}-t_{j}^{+}}^{t_{D}-t_{i}^{-}-t_{i j}} \lambda e^{-\lambda \tau} d \tau=e^{-\lambda\left(t_{D}-t_{j}^{+}\right)}-e^{-\lambda\left(t_{D}-t_{i}^{-}-t_{i j}\right)} & t \in\left[t_{o}, t_{i}^{+}-t_{i j}\right)
\end{array}\right.
\end{aligned}
$$

$P\left(e_{i j}, t\right)^{\text {non-vehicular }}=$ probability of moving along link $i j$ by non-vehicular travel mode.

$\varphi\left(t_{i}^{-}\right)=$probability of node $i$ at $t_{i}^{-}$.

$\varphi\left(t_{i}^{+}\right)=$probability of node $i$ at $t_{i}^{+}$.

$P\left(e_{i j}, t\right)$ vehicular $=$ probability of moving along link $i j$ by vehicular travel mode.

$P_{O \rightarrow i}(t)=$ probability of reaching node $i$ from the origin.

$P_{j \rightarrow D}(t)=$ probability of reaching the destination from node $j$.

$t_{i}^{-}=$the earliest arrival time at node $i$.

$t_{i}^{+}=$the latest departure time at node $i$.

$t_{i j}=$ travel time from node $i$ to node $j$.

$t_{D}=$ start time of activity at the destination.

$t_{O}=$ end time of activity at the origin.

$t=$ a time in the range of $\left[t_{O}, t_{D}\right]$.

$\sigma=$ parameter shows the movement level of the mobile object according to time-space restrictions.

$\lambda=$ parameter of the exponential distribution. 
According to Song et al. (2016), for non-vehicular movements, due to the limited time budget, maximum moving speed, and pressure of arriving at the destination before the planned time, probability of movements does not obey the standard distribution and is expected to be biased toward the destination. Thus, the probability of moving along edge $i j$ is considered as the joint probability of that edge at $t_{D}-t$ and $t-t_{O}$ (equation 2 and equation 3). Accordingly, the normalized edge probabilities are calculated by equation 1 . For vehicular movement, because of one-way and turn restrictions, and speed limits, the mobile object is not free to move backward and forward. Hence, in this case, instead of BB, Markov process is adopted for considering movement probability and holding time in an integrated framework. In this regard, the diffusion process from the origin, which shows the dependency of the passing probability to the available arrival time at that location, is modeled by equation 5 and similarly, the diffusion process from that location to the destination is represented by equation 6 . Therefore, the probability of movement from vertex $i$ to vertex $j$ and vertex $j$ to vertex $i$ along the edge $i j$ at $t$ is measured by equation 4 .

For demonstrating accessibility of an object to edges of a road network relative to activities, equations 1 and 4 are adopted. According to Horner and Downs (2014) and considering opportunity-based measures, combination of the visiting probability of each edge and the attractiveness of activities located at these links, $O_{k}$, shows accessibility of an object to urban opportunities. Therefore, the accessibility level of object or group $l$ to activity $k$ by mode $m$ located along edge $i j$ at time $t \in\left[t_{O}, t_{D}\right]$ is defined through equation 7 :

$$
A_{l k}^{t m}=P\left(e_{i j}, t\right)_{l}^{m} \times O_{k}
$$

$O_{k}=$ attractiveness of opportunity $k, O_{k}=\frac{o_{k}}{\max \left(O_{k}\right)}$.

$P\left(e_{i j}, t\right)_{l}^{m}=$ visiting probability of link $e_{i j}$ by person $l$ by mode $m$ at $t$.

$m=\{$ vehicular,non-vehicular $\}$.

In equation 7 , component $P\left(e_{i j}, t\right)_{l}^{m}$ not only calculates the attendance probability of an edge, but also shows feasible opportunity space under space-time constraints. The first and second parts of this equation, respectively, show individual- and opportunity-related characteristics representing blended nature of the proposed model. Accessibility of object $l$ to opportunity $k$ and accessibility of activities by individual(s) at $t \in\left[t_{O}, t_{D}\right]$ are respectively computed through equation 8 and equation 9.

$$
\begin{aligned}
& A A_{l}^{t}=\sum_{k=1}^{K} A_{l k}^{t} \\
& P A_{k}^{t}=\sum_{l=1}^{L} A_{l k}^{t}
\end{aligned}
$$

An example of accessibility calculation with this metric is elaborated for an individual with a hypothetical trip. This person starts his/her trip from an origin (red spot in Figure 1) to a destination (blue spot in Figure 1) within 20 minutes in a street network including 3064 links. Figure 1 illustrates the distribution of stationary activities (larger ones have higher attractiveness) and the layout of the road network. Figure 2(a) shows the accessibility level of opportunities in $5 \mathrm{~min}, 10 \mathrm{~min}$, and $15 \mathrm{~min}$ time steps. 


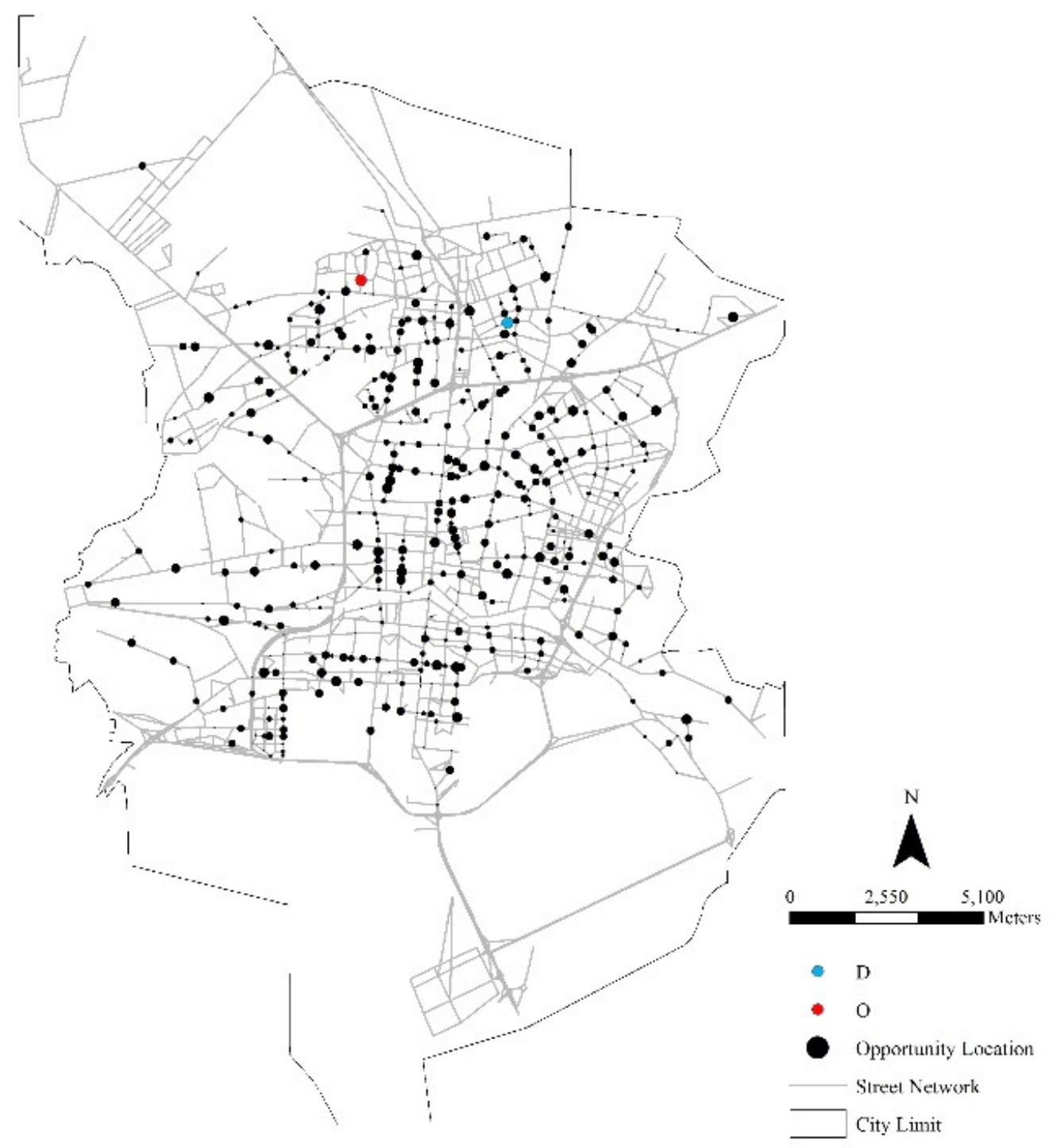

Figure 1. Characteristics of the hypothetical case

According to equation $8, A A_{l}^{t}$ for this traveler can be calculated as the sum of perceived accessibility, that is equal to $0.000159,0.000206$, and $0.000232 \mathrm{for} 5 \mathrm{~min}, 10 \mathrm{~min}$, and $15 \mathrm{~min}$ time lags, respectively. 
To put the model in the context of accessibility modeling, it is useful to refer to the works of Lenntorp (1977), Kwan (1998), and studies by El-Geneidy and Levinson (2006) and Neutens et al., (2010). The proposed measure is in line with their pieces of research where two approaches may be identified. The first is enumerating the number of opportunities in the feasible opportunity space (FOS) under a person's budget constraint and the second is summing the attraction of activities within FOS. In both of these approaches, the only characteristic that matters for considering an opportunity in accessibility calculation is its existence in FOS. None of the identified activities are weighed in these measures, despite the fact that all activities in STP or NTP are not equally accessible (e.g., with the same attractiveness, opportunities which are closer to the boundary of NTP/STP are less accessible than that of more distant ones (Song et al., 2016; Winter \& Yin, 2010)). The main differences of the proffered model are as follows (1) the binary nature of the previous metrics leading to overestimation effect was mitigated by adding a correction factor, and (2) individual- and opportunity-related aspects were linked in a unified dynamic framework. Figure 2(b) depicts the accessibility value of the aforementioned traveler quantified by the widely used binary measure, NUMOA (number of opportunities in FOS with the effect of attractiveness), in transportation planning formulated in equation 10 (El-Geneidy \& Levinson, 2006; Hanson \& Schwab, 1987) and NUMO (number of opportunities in FOS) indicated by Neutens et al. (2010) (equation 11) with a little modification.

$$
\begin{gathered}
\text { NUMOA } A^{t}=\sum_{k=1}^{K} B_{k} \times O_{k},\left\{\begin{array}{r}
B_{k}=1, \text { if } O_{k} \text { be within the NTP computed in } t \\
B_{k}=0, \text { otherwise }
\end{array}\right. \\
N U M O^{t}=\sum_{k=1}^{K} B_{k},\left\{\begin{array}{c}
B_{k}=1, \text { if } O_{k} \text { be within the NTP computed in } t \\
B_{k}=0, \text { otherwise }
\end{array}\right.
\end{gathered}
$$

Table 1 represents the accessibility values measured by equation 8 , equation 10, and equation 11 . Comparison of the outputs shows that the value obtained by the proposed model was smaller than NUMO and NUMOA because opportunities are balanced by the value of visiting probability that takes parameters such as pressure of reaching the destination into account. 

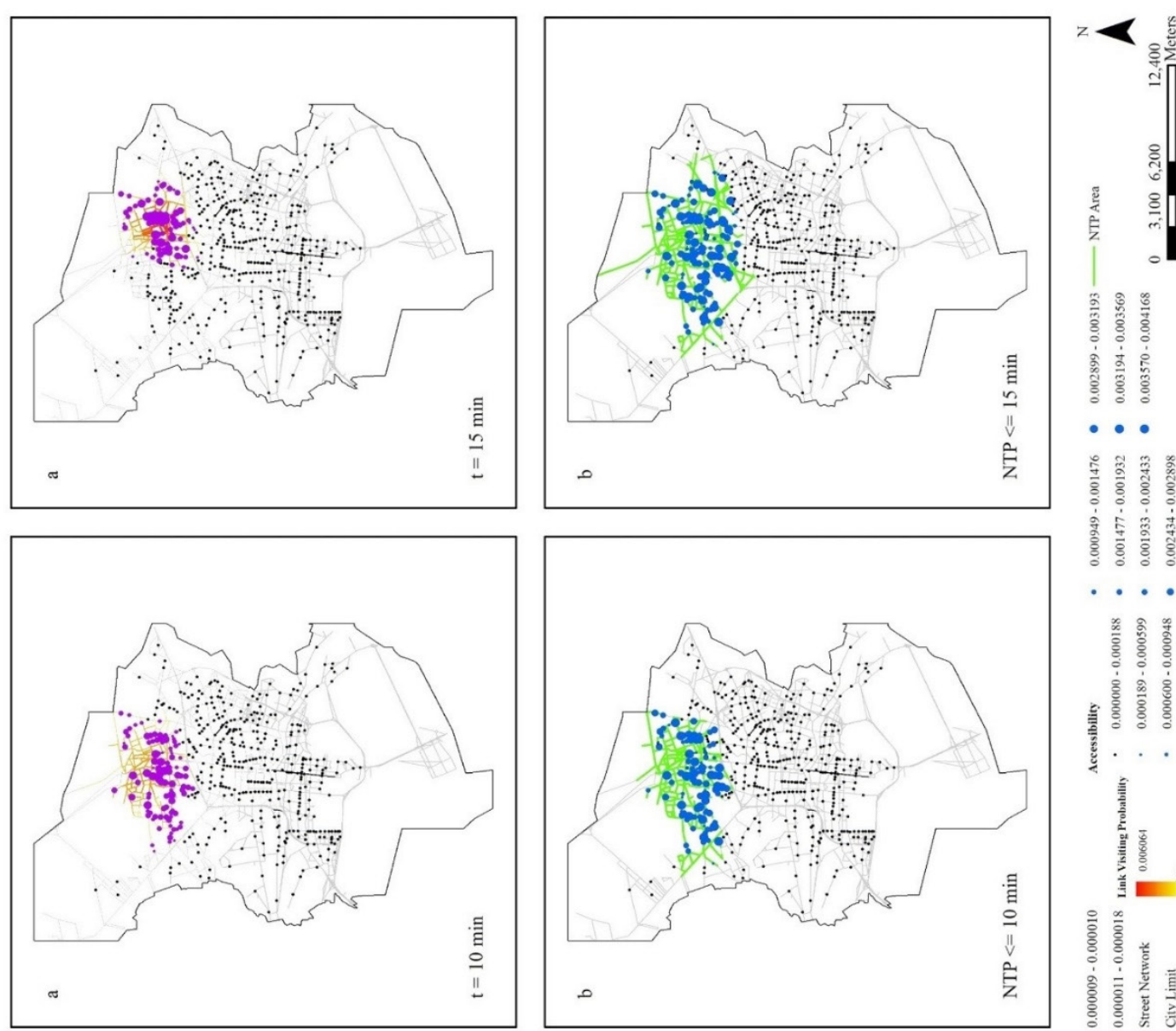

…

善善害

褰

列.
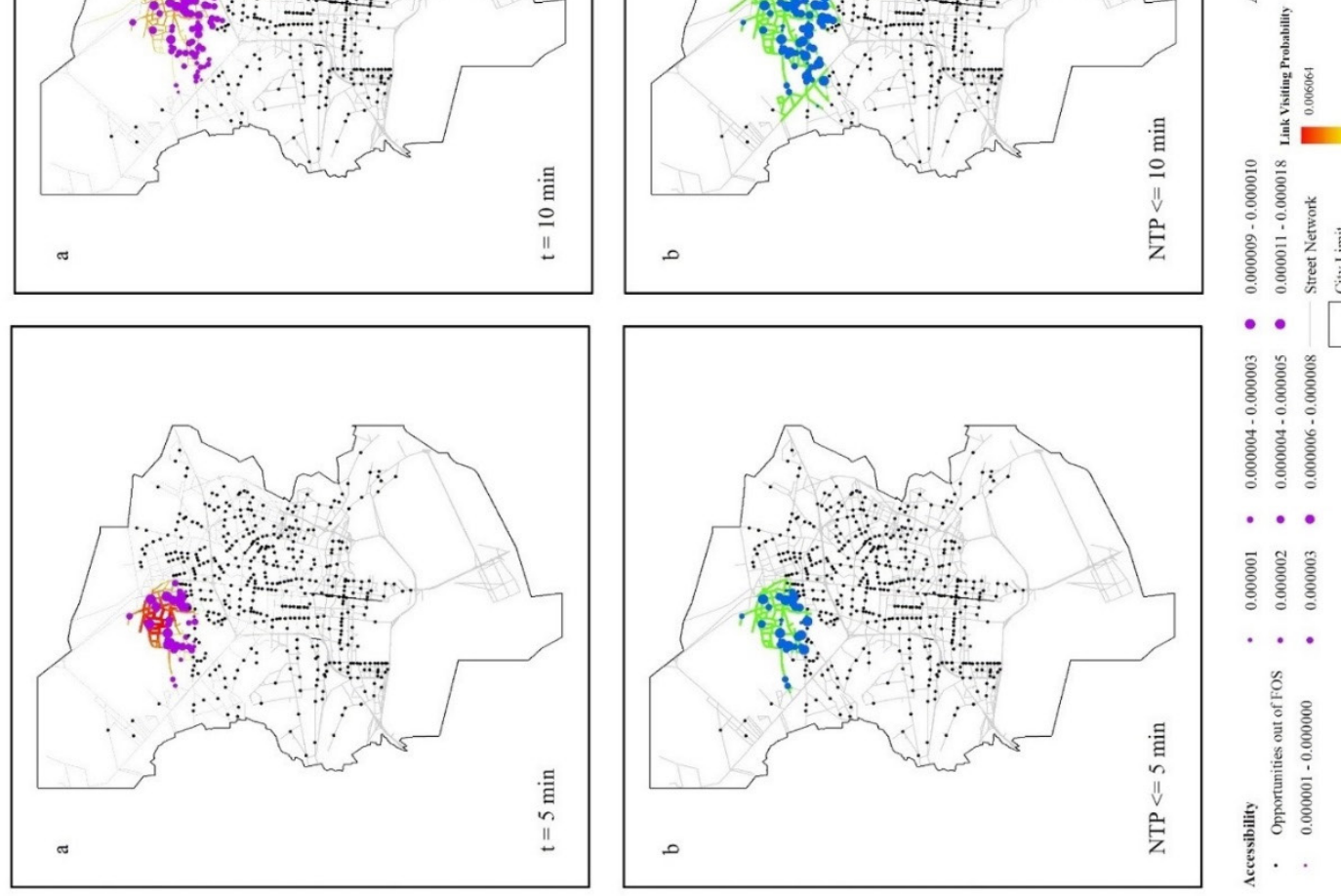

Figure 2. (a) accessibility of an individual to opportunities obtained by the proposed model, (b) accessibility of an individual to opportunities by NUMO and NUMOA 
Table 1. Comparison of the proposed model with NUMOA and NUMO

\begin{tabular}{|c|c|c|c|c|c|c|c|c|}
\hline \multirow[b]{2}{*}{$\begin{array}{l}\text { Time } \\
\text { step }\end{array}$} & \multicolumn{4}{|c|}{$A A_{l}^{t}$ vs. $N U M O A^{t}$} & \multicolumn{4}{|c|}{$\dagger N A A_{l}^{t}$ vs. $N U M O^{t}$} \\
\hline & $A A_{l}^{t}$ & $N U M O A^{t}$ & $\begin{array}{l}\text { Deviation } \\
\text { (value) }\end{array}$ & $\begin{array}{l}\text { Deviation } \\
(\%)\end{array}$ & $N A A_{l}^{t}$ & $N U M O^{t}$ & $\begin{array}{l}\text { Deviation } \\
\text { (value) }\end{array}$ & $\begin{array}{l}\text { Deviation } \\
(\%)\end{array}$ \\
\hline $\begin{array}{l}\mathrm{t}=5 \\
\min \end{array}$ & 0.000159 & 0.069512 & 0.069353 & 99.77 & 29 & 31 & 2 & 6.45 \\
\hline $\begin{array}{l}t=10 \\
\min \end{array}$ & 0.000206 & 0.215142 & 0.214936 & 99.90 & 85 & 102 & 17 & 16.66 \\
\hline $\begin{array}{l}\mathrm{t}=15 \\
\mathrm{~min}\end{array}$ & 0.000232 & 0.285029 & 0.284797 & 99.91 & 76 & 139 & 63 & 45.32 \\
\hline
\end{tabular}

$\dagger$ Note: $N A A_{l}^{t}$ is the number of opportunities identified in $A A_{l}^{t}$.

\section{$4 \quad$ Model specification and application}

To show the applicability of the developed metric in real environments, in this part of paper, study area and constraints affecting the available time and the characteristics of land-use and transportation systems are represented.

\subsection{Study area and data preparation}

Food desert has negative impact on residents and increases the risk of getting some diseases such as: diabetes, cancer, and hyper-tension (Bazzano et al., 2002; He et al., 2004; Hung et al., 2004; Leal \& Chaix, 2011). In this regard, it is very important to provide spatial access to healthy food for citizens (Widener, Farber, Neutens, \& Horner, 2015). To provide accessibility to healthy food for residents of Isfahan, the municipality started to establish and manage Kowsar retail markets that supply daily and weekly needs of different households with various socio-economic levels from low- to middle- and highincome families (Chegounian, 2016).

Recently, municipality pursues two policies targeting enhancement of temporal accessibility to these markets in a WH (work to home) trip sequence taking place in a time window starting at 5:00 p.m. and ending at 8:00 p.m. The reason for opting to WH trip chain and this time span is that the most frequent shopping from these markets are carried out in WH trips from 5:00 p.m. to 8:00 p.m. The aim of the first policy, "market exclusion and area expansion", is to determine and exclude a market with the smallest temporal accessibility value and to analyze the effect of expanding the area of each remained market on the level of accessibility. The purpose of the second policy, "new market construction", is to suggest place or places with the highest potential accessibility for building a new market with predefined level of attractiveness. It is apparent that for assessing the above mentioned policies, a space-time measure, which is able to calculate accessibility value in different moments of time, is required. Hence, in this paper, the spatial accessibility of people living in the city of Isfahan to these markets is pondered by the proposed model to show its applicability in real situations.

Configuration of the streets and passing time through each link were acquired from Transportation Research Center of Isfahan University of Technology (TRCIUT). Area of the markets that was consid- 
ered as the representative of opportunities attractiveness was obtained from the city municipality (Table 2 and Figure 3). As Kowsar markets are highly vehicular-dependent and trips by non-vehicular modes are very rare (Chegounian, 2016), non-vehicular model was excluded from the computation process and $\lambda$, the parameter of vehicular model, was specified to be 0.016 (see Appendix A for the parameter estimation process). Visiting probability and accessibility to the markets were calculated by a program developed in MATLAB and ArcGIS 10.3 was applied for output visualization. The produced program was distributed on 60 processors and processing was about 7 hours and 24 minutes that is a significant amount of time-saving, compared to a desktop PC (personal computer).

Table 2. Attractiveness of opportunities (standardized according to equation 7)

\begin{tabular}{lllllllllllllll}
\hline $\begin{array}{l}\text { Opportu- } \\
\text { nity ID }\end{array}$ & 1 & 2 & 3 & 4 & 5 & 6 & 7 & 8 & 9 & 10 & 11 & 12 & \\
\hline $\begin{array}{l}\text { Attrac- } \\
\text { tiveness }\end{array}$ & 0.372439 & 0.09311 & 0.18622 & 1 & 0.333333 & 0.204842 & 0.540037 & 0.651769 & 0.260708 & 0.286778 & 0.20298 & 0.484171 \\
\hline
\end{tabular}

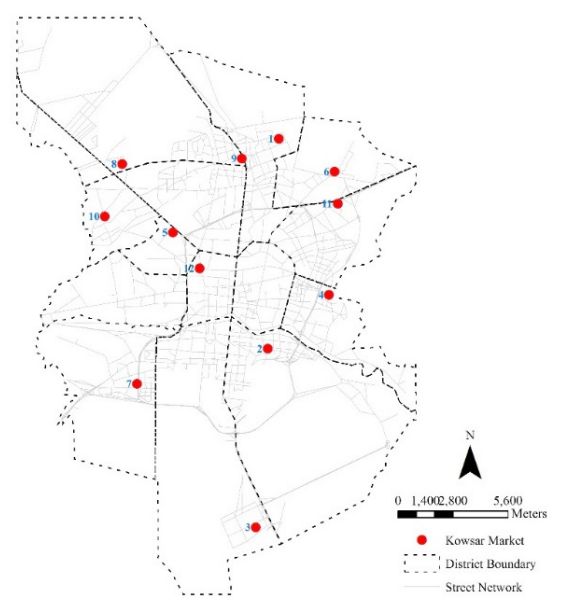

Figure 3. Location of Kowsar markets and configuration of streets in the city of Isfahan

\subsection{Results}

Results of the model implementation are presented as follows:

\subsubsection{First policy: Market exclusion and area expansion}

Given the origin and destination of $26646 \mathrm{WH}$ trips, accessibility of individuals to the markets was calculated by equation 8 , and accessibility of opportunities was computed through equation 9 . Table 3 shows $P A_{k}^{t}$ along the rank of markets on the basis of the accessibility values. Figure 4 portrays accessibility distribution at $\mathrm{t}=45, \mathrm{t}=90$, and $\mathrm{t}=135$ after departure time. This figure displays that markets 4 and 2 had the maximum and minimum accessibility value among the other opportunities, respectively. 
Table 3. Accessibility to Kowsar markets at 45, 90, and 135 minutes after departure time (Blue shadings are for the maximum and the gray ones are for the minimum values)

\begin{tabular}{lllllll}
\hline \multirow{2}{*}{ Market ID } & $\mathrm{t}=45 \mathrm{~min}$ & & $\mathrm{t}=90 \mathrm{~min}$ & \multicolumn{1}{c}{$\mathrm{t}=135 \mathrm{~min}$} & \\
\cline { 2 - 7 } & $P A_{k}^{t}$ & Rank & $P A_{k}^{t}$ & Rank & $P A_{k}^{t}$ & 6 \\
\hline 1 & 18.328621 & 6 & 28.664336 & 6 & 11.862297 & 6 \\
2 & 4.741958 & 12 & 8.608601 & 12 & 5.65255 & 12 \\
3 & 8.322179 & 11 & 18.273173 & 10 & 9.40388 & 9 \\
4 & 55.96146 & 1 & 93.091866 & 1 & 56.916847 & 1 \\
5 & 19.174707 & 5 & 28.922627 & 5 & 14.280072 & 5 \\
6 & 11.70418 & 10 & 17.665152 & 11 & 8.632752 & 10 \\
7 & 24.173333 & 4 & 45.734924 & 4 & 27.768045 & 3 \\
8 & 31.960439 & 2 & 51.911633 & 2 & 24.24788 & 4 \\
9 & 14.215973 & 7 & 20.741751 & 8 & 8.344916 & 11 \\
10 & 13.81484 & 8 & 23.047484 & 7 & 11.302312 & 7 \\
11 & 12.05859 & 9 & 18.453161 & 9 & 9.970842 & 8 \\
12 & 28.742281 & 3 & 47.426947 & 3 & 30.59998 & 2 \\
\hline
\end{tabular}



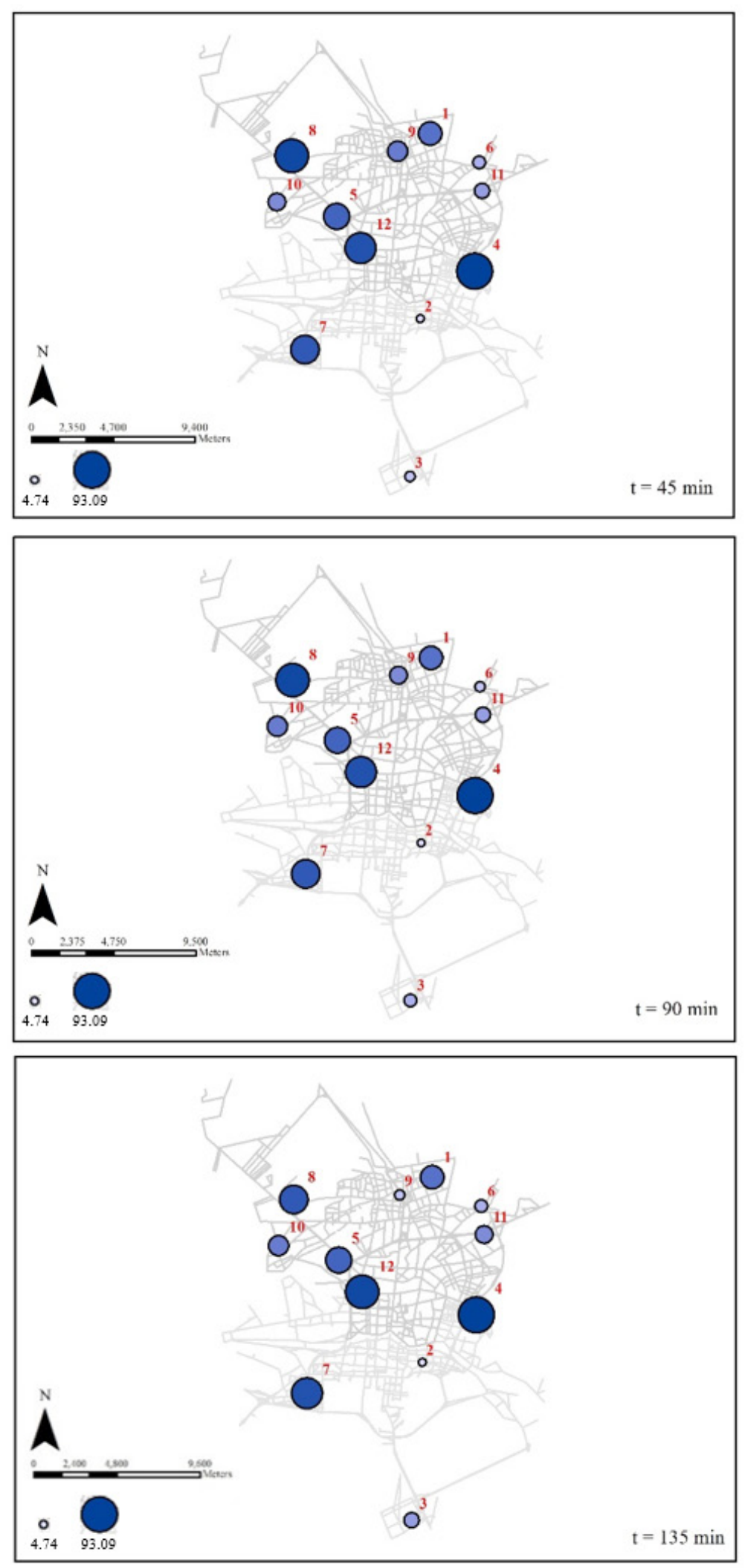

Figure 4. Aggregated accessibility to the markets $\left(P A_{k}^{t}\right)$ 
In addition, it could be seen that, compared to the traditional models, activities with higher attractiveness did not necessarily have higher accessibility level. For instance, market 6 had the ninth rank in terms of attractiveness while it had the tenth and eleventh ranks in terms of accessibility level. For more analysis of this observation, another simulation was executed. Figure 5 illustrates the results of the model execution for five activities distributed in the context of street network along with their attraction and temporal accessibility. In this figure, opportunity T2 has larger attraction than T1, and T1 is adjacent to a link with higher level of visiting probability. At the moments of $t=45$ and $t=135$ and in total case, accessibility of T1 with smaller attraction was larger than T2. To test the correlation between attraction and accessibility, rho coefficient was calculated by Spearman's test. The outputs represented that the correlation between attraction and level of accessibility was not significant at $\mathrm{t}=45$, at $\mathrm{t}=135$, and in the case of total accessibility (Table 4), but at $\mathrm{t}=90$, correlation between attraction and accessibility was confirmed. This result is analytically justifiable. Links of a street network have visiting probability depending on the spatiotemporal constraints. By changing costs of links, the shortest paths vary from the origin to the starting point of a link and from the end point of a link to the destination. As a place with larger attraction may be located next to a link with smaller value of visiting probability and accessibility of the place is measured by the combination of visiting probability and attractiveness, its level of accessibility may be smaller than a place situated by a link with larger visiting value and smaller attraction. Furthermore, in models like NUMOA, opportunities in NTP with larger attraction certainly have higher accessibility than opportunities with smaller attraction. However, regarding the effect of visiting probability and the number of individuals in the calculation process, accessibility of a more attractive location may be adjusted and be equal or even smaller than opportunities with smaller attractiveness.
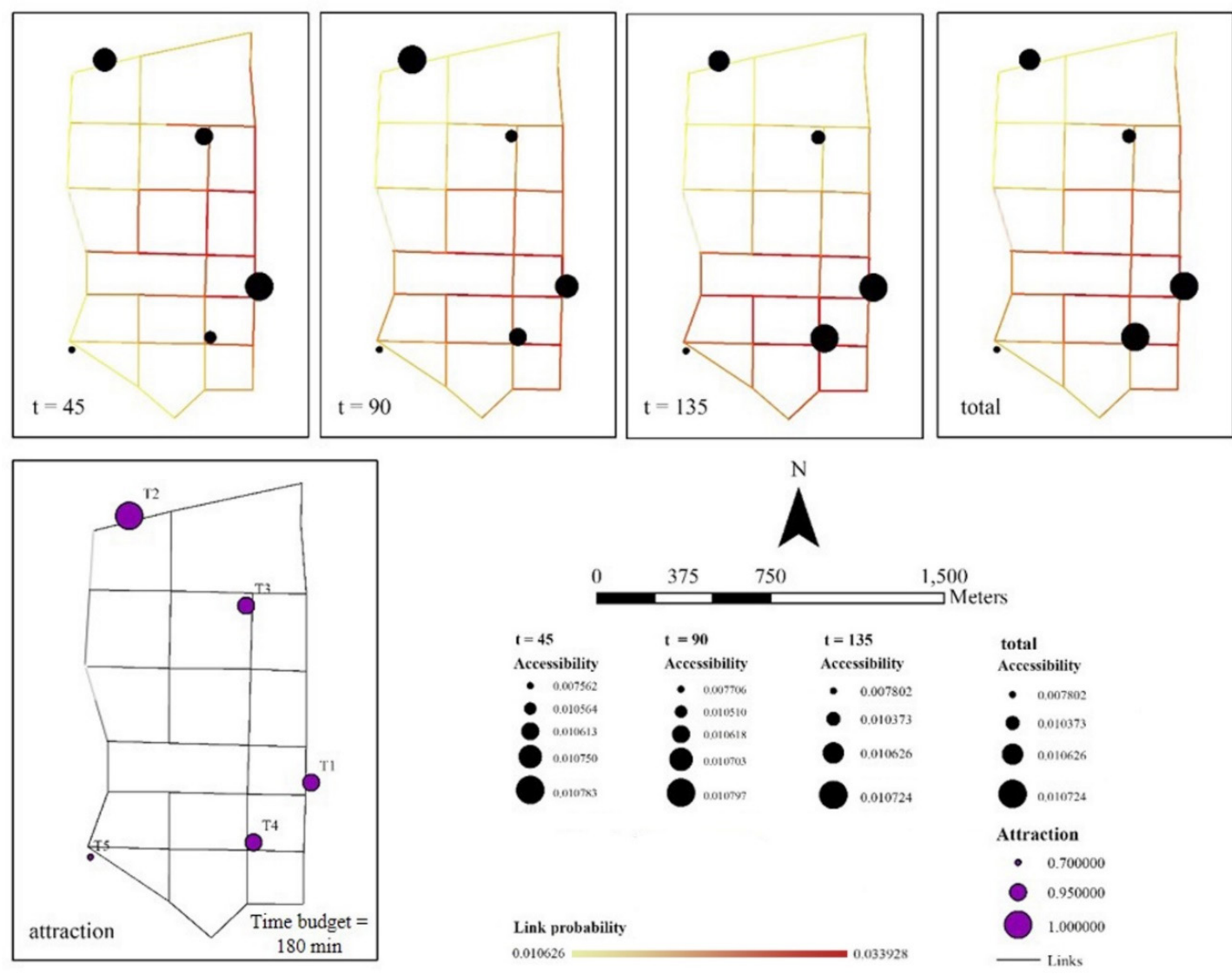

Figure 5. More analysis for relationship between attraction and accessibility 
Table 4. Spearman's test for attraction and accessibility

\begin{tabular}{llllll}
\hline & & $\begin{array}{l}\text { Accessibility in } \\
\mathrm{t}=45\end{array}$ & $\begin{array}{l}\text { Accessibility in } \\
\mathrm{t}=90\end{array}$ & $\begin{array}{l}\text { Accessibility in } \\
\mathrm{t}=135\end{array}$ & Total accessibility \\
\cline { 2 - 6 } Attraction & 0.671 & 0.894 & 0.459 & 0.671 \\
\cline { 2 - 5 } & Sorrelation & 0.215 & 0.041 & 0.437 & 0.215 \\
\hline
\end{tabular}

After identification of the market with the smallest accessibility value, i.e., market 2, municipality of Isfahan needs to see how the accessibility changes if this market is closed and in exchange, the area of one of the remained markets be doubled. In this regard, the model ran for each of the defined area expansion scenarios, i.e., area duplication of one market while the area of the others remains the same. Table 5 reports changes of accessibility versus variations in the opportunities attractiveness.

The comparison of the results of each scenario with the base values that are accessibility of opportunities after excluding market 2 without change in attractiveness of the other markets along with time-steps-based comparison of cases, revealed that if the area of market 7 is doubled, accessibility in two time instants will be maximized. However, the maximum total accessibility is when market 8 is doubled. Minimum accessibility values, in terms of both total and the number of instants with maximum accessibility, occurred when market 4 was expanded. Furthermore, it can be seen that if the area of markets 4, 7, and 8 changes, attractiveness of the other opportunities will be modified and consequently the accessibility values will be varied. However, in the other scenarios only the accessibility of the expanded market changed and the accessibility of the other markets remains the same as the base values (See appendix B for the outputs of accessibility calculation in details). 
Table 5. Accessibility to the markets in the first policy (Grey and blue colors respectively show the minimum and maximum values in all cases)

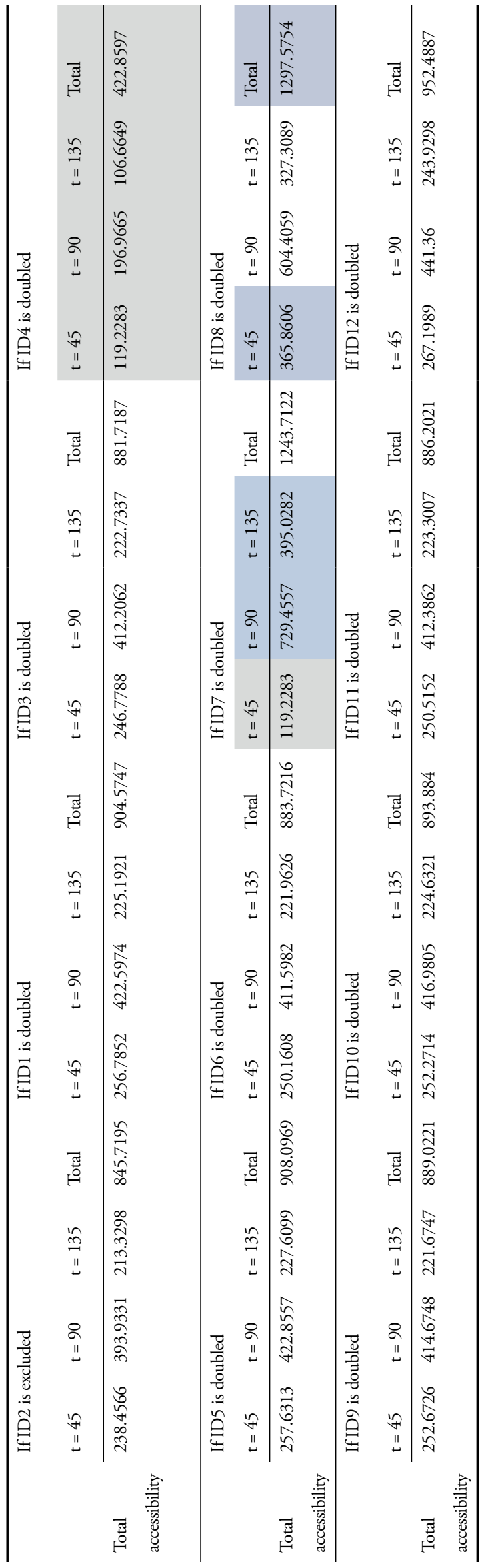


To identify the most balanced case, standard deviation of the accessibility values at each time step was calculated. Table 6 denotes the values calculated for this statistical indicator. The results depict that the most balanced state is achieved when area of market 4 is doubled. However, this scenario gives the smallest total accessibility value.

Table 6. Standard deviation of accessibility values for the first policy

\begin{tabular}{|c|c|c|c|c|c|c|c|c|}
\hline \multicolumn{3}{|c|}{ If market 1 is doubled } & \multicolumn{3}{|c|}{ If market 2 is excluded } & \multicolumn{3}{|c|}{ If market 3 is doubled } \\
\hline$t=45$ & $\mathrm{t}=90$ & $\mathrm{t}=135$ & $\mathrm{t}=45$ & $\mathrm{t}=90$ & $\mathrm{t}=135$ & $\mathrm{t}=45$ & $\mathrm{t}=90$ & $\mathrm{t}=135$ \\
\hline 14.23103 & 23.53205 & 14.66733 & 13.57424 & 22.80438 & 14.83935 & 12.97407 & 22.05214 & 14.4726332 \\
\hline \multicolumn{3}{|c|}{ If market 4 is doubled } & \multicolumn{3}{|c|}{ If market 5 is doubled } & \multicolumn{3}{|c|}{ If market 6 is doubled } \\
\hline $\mathrm{t}=45$ & $\mathrm{t}=90$ & $\mathrm{t}=135$ & $\mathrm{t}=45$ & $\mathrm{t}=90$ & $\mathrm{t}=135$ & $\mathrm{t}=45$ & $\mathrm{t}=90$ & $\mathrm{t}=135$ \\
\hline 6.787118 & 11.40219 & 7.419673 & 14.42515 & 23.58463 & 14.97131 & 13.16687 & 22.0067 & 14.4361345 \\
\hline \multicolumn{3}{|c|}{ If market 7 is doubled } & \multicolumn{3}{|c|}{ If market 8 is doubled } & \multicolumn{3}{|c|}{ If market 9 is doubled } \\
\hline $\mathrm{t}=45$ & $\mathrm{t}=90$ & $\mathrm{t}=135$ & $\mathrm{t}=45$ & $t=90$ & $\mathrm{t}=135$ & $\mathrm{t}=45$ & $\mathrm{t}=90$ & $\mathrm{t}=135$ \\
\hline 6.787118 & 42.22744 & 27.47839 & 20.82676 & 34.98844 & 22.7678 & 13.46909 & 22.28528 & 14.4255609 \\
\hline \multicolumn{3}{|c|}{ If market 10 is doubled } & \multicolumn{3}{|c|}{ If market 11 is doubled } & \multicolumn{3}{|c|}{ If market 12 is doubled } \\
\hline$t=45$ & $t=90$ & $\mathrm{t}=135$ & $t=45$ & $t=90$ & $\mathrm{t}=135$ & $t=45$ & $\mathrm{t}=90$ & $\mathrm{t}=135$ \\
\hline 13.41211 & 22.57191 & 14.61263 & 13.20151 & 22.06651 & 14.50702 & 17.31967 & 28.89108 & 19.3368203 \\
\hline
\end{tabular}

It must be noted that there are some items left for further research. For example, as well as visiting probability, attractiveness of opportunities might be changed during the time and might be dynamic. In addition, attractiveness can be bounded by capacity variable and competition effect.

\subsubsection{Second policy: New market location}

Isfahan has a monocentric spatial structure and a large portion of shopping activities for supplying daily and weekly needs is done by WH trips in the afternoon times. These trips are mainly originated in the central areas and destined in the peripheral districts. In this way, the municipality likes to have a set of locations including areas in $L=\left\{1000 \mathrm{~m}^{2}, 2000 \mathrm{~m}^{2}, 3000 \mathrm{~m}^{2}\right\}$ with the highest level of potential accessibility to respond the shopping demand of citizens and to deliver better services to people with this kind of trip. Having this set of locations, the local government is able to choose a solution from the others, considering construction factors such as: available monetary budget, land ownership, land price, etc.

In doing so, places with areas equal to the elements in $L$ with the largest visiting probability values need to be selected to maximize equation 7 . As the area of markets was given, firstly, visiting probability of each segment in the street network was calculated at three time instants. Figure 6(a) illustrates the visiting probability of links in the study area and Figure 6(b) shows the links that are common among the simulated states with the highest probability values. Secondly, locations with the area of 1000, 2000, and 3000 square meters adjacent to the segments with the highest probability were determined. Figure 7 displays the founded places and their rank of accessibility in each group of $L$ independent from the other identified locations for new construction and other markets in the study area.

To compare the first policy with the second policy, the accessibility of markets shown in Figure 7 was computed considering the other opportunities in the study area when market 2 was removed from the set of available markets without any intervention in other conditions of the current state. Table 7 represents the difference between the obtained values in the second policy and the best values in the first policy depicted in Table 5. Result of comparing the second policy with the best cases of the first policy 
shows that construction of market L_3000_3 gives the largest accessibility value, and the best value of the first policy that is area expansion of the market with ID 8 has better value than the best of the second policy.

It must be noted that these policies were analyzed in terms of accessibility, and for selecting a case in each policy, the results can be combined with the cost-benefit studies including other socio-economic factors. Integrating these complementary studies into the model structure can be investigated in future works.
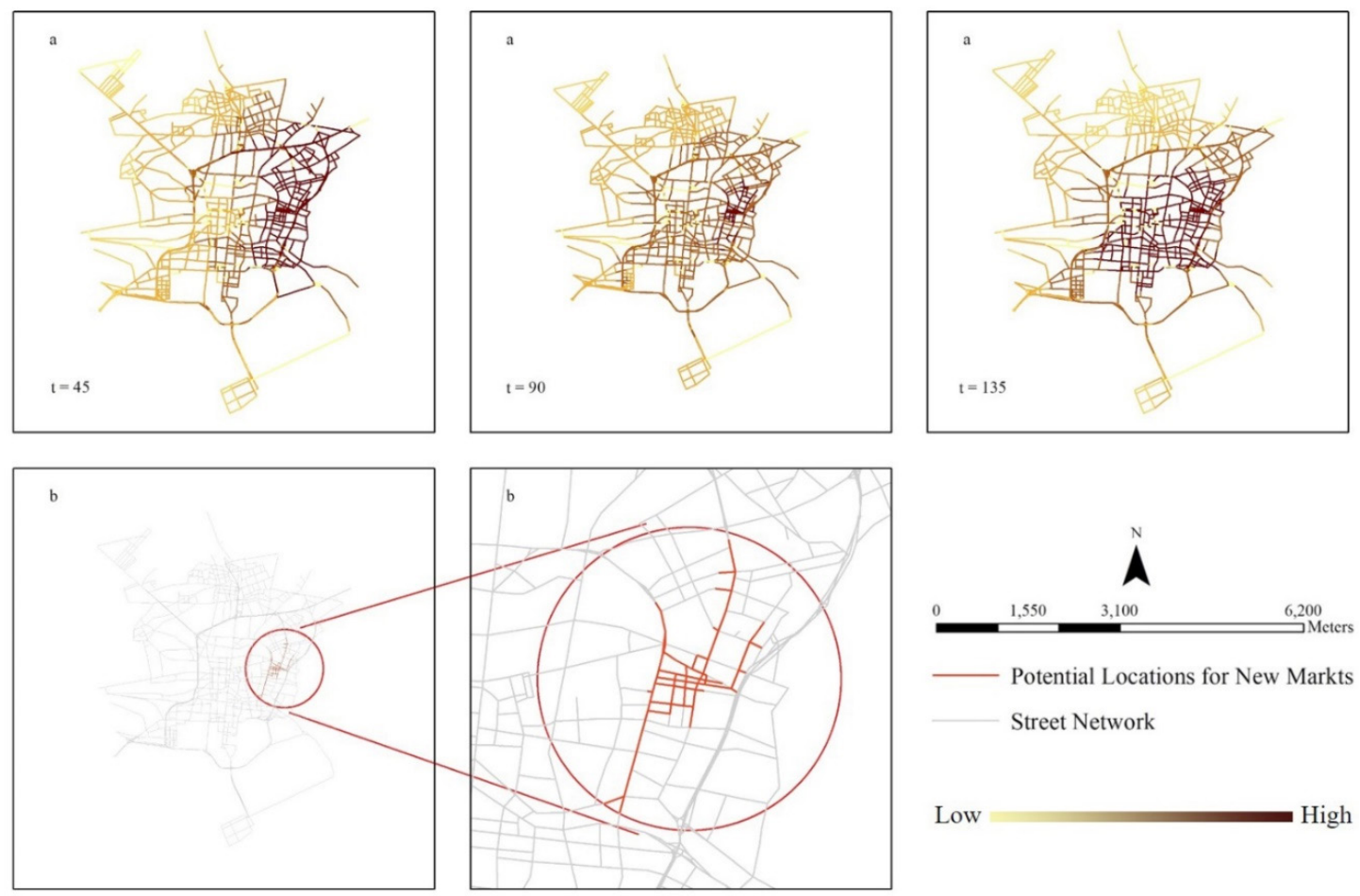

Figure 6. (a) Distribution of visiting probabilities along the street network, (b) links with the highest level of probability. These links are the intersection of the three simulated states with respect to the maximum probability value 


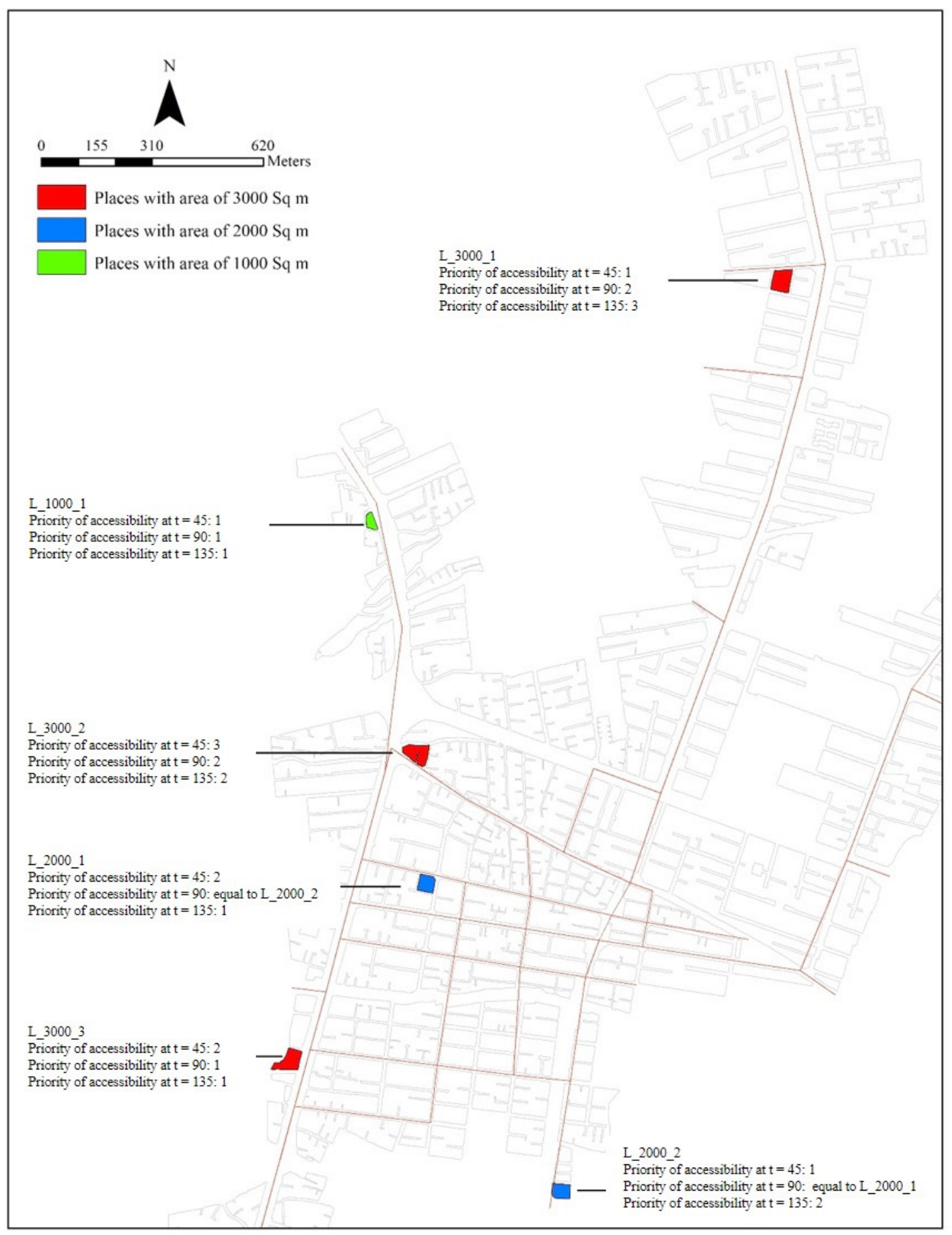

Figure 7. Rank of places determined in the second policy in terms of accessibility value 
Table 7. Difference between the outputs of the second policy with the best cases of the first policy. Attractiveness of the opportunities are standardized by the formula given for $O_{k}$ in equation 7. Cells with blue shading and border are cases that have the largest accessibility values in the second policy

\begin{tabular}{|c|c|c|c|c|c|c|c|c|c|c|c|c|}
\hline \multirow[b]{3}{*}{ ID } & \multicolumn{12}{|c|}{ Accessibility values } \\
\hline & \multicolumn{3}{|c|}{$\mathrm{t}=45$} & \multicolumn{3}{|c|}{$t=90$} & \multicolumn{3}{|c|}{$\mathrm{t}=135$} & \multicolumn{3}{|c|}{ total } \\
\hline & Case value & $\begin{array}{l}\text { Best of } \\
\text { policy } 1\end{array}$ & Difference & Case value & $\begin{array}{l}\text { Best of } \\
\text { policy } 1\end{array}$ & Difference & Case value & $\begin{array}{l}\text { Best of } \\
\text { policy } 1\end{array}$ & Difference & Case value & $\begin{array}{l}\text { Best of } \\
\text { policy } 1\end{array}$ & Difference \\
\hline L_1000_1 & 257.7561 & 365.860 & 108.1045 & 426.4400 & 729.4557 & 303.0157 & 21.2679 & 234.597723 & 213.3298 & 705.464 & 1297.575 & 592.1114 \\
\hline L_2000_1 & 270.7632 & \multirow{2}{*}{365.860} & 95.09737 & 449.9279 & \multirow{2}{*}{729.4557} & 279.5278 & 35.96068 & \multirow{2}{*}{234.597723} & 213.3298 & 756.6518 & \multirow{2}{*}{1297.575} & 540.9236 \\
\hline L_2000_2 & 270.2691 & & 95.59149 & 448.0514 & & 281.4043 & 34.52901 & & 213.3298 & 752.8496 & & 544.7258 \\
\hline L_3000_1 & 291.2887 & \multirow{3}{*}{365.860} & 74.5719 & 476.3906 & \multirow{3}{*}{729.4557} & 253.0651 & 49.22865 & \multirow{3}{*}{234.597723} & 213.3298 & 816.9079 & \multirow{3}{*}{1297.575} & 480.6675 \\
\hline L_3000_2 & 287.6866 & & 78.17393 & 476.0325 & & 253.4232 & 53.90196 & & 213.3298 & 817.6212 & & 479.9542 \\
\hline L_3000_3 & 287.0455 & & 78.81505 & 477.4345 & & 252.0212 & 55.55298 & & 213.3298 & 820.0330 & & 477.5424 \\
\hline
\end{tabular}

\section{$5 \quad$ Discussion and conclusion}

Considering the literature on accessibility modeling and time geography, this paper has fostered an accessibility measure using the frameworks of Horner and Downs (2014) and Song et al. (2016). This measure can be applied to analyze the accessibility in both retrospective and prospective ways and mitigate the overestimation effect existed in the previous metrics by taking the movement principles and stochastic processes into account. In addition, in the proposed model, it was attempted to connect people- and place-based measures together because despite the necessity of working in this area (Horner \& Downs, 2014), scant studies throughout the literature have been dedicated to develop blended models (Miller \& Wu, 2000; Neutens, Delafontaine, Scott, \& De Maeyer, 2012). The model can be aggregated over individuals or places to derive individual- or opportunity-based accessibility value. It means that the model can play a role in both person- and place-based arenas.

As mentioned before, the proposed model has some similarity with previous models such as NUMO and NUMOA, but the context of the adopted approach (appending a probabilistic component to the model's structure) in pondering and mapping accessibility makes it different from its precedents. However, it must not be said that this model is not necessarily better or worse than other methods, but it is another perspective alongside the other approaches at least.

Several applications can be considered for the proposed model. For example, it can be regarded for analyzing the effects of changes in the road network (e.g., adding a new road segment or increase in streets' level of service) on individual's route choice and consequently accessibility or the effect of constructing a new opportunity on the accessibility level. Along with the policy analysis applications, the model can be adopted for policy-making purposes. For instance, by using optimization techniques, an analyst can suggest the optimum travel time, departure time, or arrival time for maximum level of accessibility or find the best location of activities for improving accessibility value. These sorts of reports can guide managers and planners to schedule activities and make activity distribution plans.

The following extensions can be regarded for future works. Although in this model accessibility of individuals traveling by vehicular mode or non-vehicular mode can be analyzed, considering the effect of mode transfer on the accessibility level and form of NTPs seems valuable as people who choose public transport for their movement mostly switch between walking, rail, and bus modes. The proposed model is a cumulative-based one, but this approach can be applied to construct measures in Burns-Miller framework (see: (Neutens et al., 2010)). Another work can be dedicated to examining the relationship 
between the socio-economic characteristics of individuals or social groups (in terms of gender, age, etc.) with their level of accessibility which reveals the way they use the space and their differences in accessibility to opportunities. In addition, the measure can be used for analyzing the potential of social interaction between different people as the model considers visiting probability and it is able to differentiate between places in terms of attending possibility. Further extension is to incorporate the effect of changes in attractiveness of opportunities during the time and cost-benefit analysis in the model structure.

\section{Acknowledgements}

The authors would like to thank the general editor, Prof. David M. Levinson, and the anonymous reviewers for their insightful and constructive comments. 


\section{References}

Banister, D. (2008). The sustainable mobility paradigm. Transport Policy, 15(2), 73-80.

Bazzano, L. A., He, J., Ogden, L. G., Loria, C. M., Vupputuri, S., Myers, L., \& Whelton, P. K. (2002). Fruit and vegetable intake and risk of cardiovascular disease in US adults: The first national health and nutrition examination survey epidemiologic follow-up study. The American Journal of Clinical Nutrition, 76(1), 93-99.

Breheny, M. J. (1978). The measurement of spatial opportunity in strategic planning. Regional Studies, 12(4), 463-479.

Burns, L. D. (1979). Transportation, temporal, and spatial components of accessibility. Geographical Analysis 13(2), 185_187. https://doi.org/10.1111/j.1538-4632.1981.tb00726.x

Cascetta, E., Cartenì, A., \& Montanino, M. (2013). A new measure of accessibility based on perceived opportunities. Procedia-Social and Behavioral Sciences, 87, 117-132.

Cerdá, A. (2009). Accessibility: A performance measure for land-use and transportation planning in the Montréal metropolitan region, supervised research project report. Montreal, Quebec: McGill University School of Urban Planning.

Chegounian, A. (2016). Land-use impact on sustainable transportation. Ishahan, Iran: Isfahan University of Technology.

Chen, B. Y., Yuan, H., Li, Q., Wang, D., Shaw, S.-L., Chen, H.-P., \& Lam, W. H. (2016). Measuring place-based accessibility under travel time uncertainty. International Journal of Geographical Information Science, 31(4),783-804.

Chen, X., \& Kwan, M.-P. (2012). Choice set formation with multiple flexible activities under spacetime constraints. International Journal of Geographical Information Science, 26(5), 941-961.

Church, R. L., \& Marston, J. R. (2003). Measuring accessibility for people with a disability. Geographical Analysis, 35(1), 83-96.

Delafontaine, M., Neutens, T., Schwanen, T., \& Van de Weghe, N. (2011). The impact of opening hours on the equity of individual space-time accessibility. Computers, Environment and Urban Systems, 35(4), 276-288.

Delafontaine, M., Neutens, T., \& Van de Weghe, N. (2012). A GIS toolkit for measuring and mapping space-time accessibility from a place-based perspective. International Journal of Geographical Information Science, 26(6), 1131-1154.

Downs, J. A. (2010). Time-geographic density estimation for moving point objects. Paper presented at the Sixth International Conference on Geographic Information Science, Zurich, September 14-17.

Downs, J. A., \& Horner, M. W. (2012). Probabilistic potential path trees for visualizing and analyzing vehicle tracking data. Journal of Transport Geography, 23, 72-80.

El-Geneidy, A. M., \& Levinson, D. M. (2006). Access to destinations: Development of accessibility measures.

Envall, P. (2007). Accessibility planning: A chimera? Leeds, England: University of Leeds.

Ettema, D., \& Timmermans, H. (2007). Space-time accessibility under conditions of uncertain travel times: Theory and numerical simulations. Geographical Analysis, 39(2), 217-240.

Farber, S., Neutens, T., Miller, H. J., \& Li, X. (2013). The social interaction potential of metropolitan regions: A time-geographic measurement approach using joint accessibility. Annals of the Association of American Geographers, 103(3), 483-504.

Ferreira, A., Beukers, E., \& Te Brömmelstroet, M. (2012). Accessibility is gold, mobility is not: A proposal for the improvement of Dutch transport-related cost-benefit analysis. Environment and Planning B: Planning and Design, 39(4), 683-697. 
Geurs, K. T., \& Ritsema van Eck, J. (2001). Accessibility measures: Review and applications. Evaluation of accessibility impacts of land-use transportation scenarios, and related social and economic impact. Bilthoven, The Netherlands: National Institute for Public Health and the Environment, Ministry of Health, Welfare and Sport.

Geurs, K. T., \& Van Wee, B. (2004). Accessibility evaluation of land-use and transport strategies: Review and research directions. Journal of Transport Geography, 12(2), 127-140.

Hägerstraand, T. (1970). What about people in regional science? Papers in Regional Science, 24(1), 7-24.

Handy, S. L. (2002). Accessibility-vs. mobility-enhancing strategies for addressing automobile dependence in the US. Berekely, CA: University of California Institute of Transportation Studies.

Hansen, W. G. (1959). How accessibility shapes land use. Journal of the American Institute of Planners, 25(2), 73-76.

Hanson, S., \& Schwab, M. (1987). Accessibility and intraurban travel. Environment and Planning A, 19(6), 735-748.

He, K., Hu, F., Colditz, G., Manson, J., Willett, W., \& Liu, S. (2004). Changes in intake of fruits and vegetables in relation to risk of obesity and weight gain among middle-aged women. International Journal of Obesity, 28(12), 1569-1574.

Horner, M. W., \& Downs, J. (2014). Integrating people and place: A density-based measure for assessing accessibility to opportunities. Journal of Transport and Land Use, 7(2), 23-40.

Hung, H.-C., Joshipura, K. J., Jiang, R., Hu, F. B., Hunter, D., Smith-Warner, S. A., ... \& Willett, W. C. (2004). Fruit and vegetable intake and risk of major chronic disease. Journal of the National Cancer Institute, 96(21), 1577-1584.

Ingram, D. R. (1971). The concept of accessibility: A search for an operational form. Regional Studies, 5(2), 101-107.

Kim, H.-M., \& Kwan, M.-P. (2003). Space-time accessibility measures: A geocomputational algorithm with a focus on the feasible opportunity set and possible activity duration. Journal of Geographical Systems, 5(1), 71-91.

Knox, P. L. (1978). The intraurban ecology of primary medical care: Patterns of accessibility and their policy implications. Environment and Planning A, 10(4), 415-435.

Kwan, M.-P., Murray, A. T., O'Kelly, M. E., \& Tiefelsdorf, M. (2003). Recent advances in accessibility research: Representation, methodology and applications. Journal of Geographical Systems, 5(1), $129-138$.

Kwan, M.-P., \& Weber, J. (2008). Scale and accessibility: Implications for the analysis of land use-travel interaction. Applied Geography, 28(2), 110-123.

Kwan, M. P. (1998). Space-time and integral measures of individual accessibility: A comparative analysis using a point-based framework. Geographical Analysis, 30(3), 191-216.

Laube, P., Imfeld, S., \& Weibel, R. (2005). Discovering relative motion patterns in groups of moving point objects. International Journal of Geographical Information Science, 19(6), 639-668.

Leal, C., \& Chaix, B. (2011). The influence of geographic life environments on cardiometabolic risk factors: A systematic review, a methodological assessment and a research agenda. Obesity Reviews, 12(3), 217-230.

Lenntorp, B. (1977). Paths in space-time environments: A time-geographic study of movement possibilities of individuals. Environment and Planning A, 9(8), 961-972.

Li, Q., Zhang, T., Wang, H., \& Zeng, Z. (2011). Dynamic accessibility mapping using floating car data: A network-constrained density estimation approach. Journal of Transport Geography, 19(3), 379-393. 
Makri, M.-C., \& Folkesson, C. (1999). Accessibility measures for analyses of land use and travelling with geographical information systems. Lund, Sweden: Department of Technology and Society, Lund Institute of Technology.

Malekzadeh, A. (2015). Measurement of transit network accessibility based on access stop choice behavior. Brisbane, Australia: Queensland University of Technology.

Miller, H. (2007). Place-based versus people-based geographic information science. Geography Compass, $1(3), 503-535$.

Miller, H. J. (1991). Modelling accessibility using space-time prism concepts within geographical information systems. International Journal of Geographical Information System, 5(3), 287-301.

Miller, H. J. (1999). Measuring space-time accessibility benefits within transportation networks: Basic theory and computational procedures. Geographical Analysis, 31(1), 1-26.

Miller, H. J., \& Bridwell, S. A. (2009). A field-based theory for time geography. Annals of the Association of American Geographers, 99(1), 49-75.

Miller, H. J., \& Wu, Y.-H. (2000). GIS software for measuring space-time accessibility in transportation planning and analysis. GeoInformatica, 4(2), 141-159.

Nastaran, M., Ghalehnoee, M., \& Sahebgharani, A. (2014). Ranking Sustainability of Urban Districts through Factor and Cluster Analyses, Case Study: Municipal Districts of Isfahan ARMANSHAHR Architecture \& Urban Development, 12(2), 177-189.

Neutens, T., Delafontaine, M., Scott, D. M., \& De Maeyer, P. (2012). An analysis of day-to-day variations in individual space-time accessibility. Journal of Transport Geography, 23, 81-91.

Neutens, T., Schwanen, T., \& Witlox, F. (2011). The prism of everyday life: Towards a new research agenda for time geography. Transport Reviews, 31(1), 25-47.

Neutens, T., Schwanen, T., Witlox, F., \& De Maeyer, P. (2010). Equity of urban service delivery: A comparison of different accessibility measures. Environment and Planning A, 42(7), 1613-1635.

O'Sullivan, D., Morrison, A., \& Shearer, J. (2000). Using desktop GIS for the investigation of accessibility by public transport: An isochrone approach. International Journal of Geographical Information Science, 14(1), 85-104.

Shen, Q. (1998). Location characteristics of inner-city neighborhoods and employment accessibility of low-wage workers. Environment and Planning B: Planning and Design, 25(3), 345-365.

Song, Y. (2015). Green accessibility: Estimating the environmental costs of space-time prisms for Sustainable Transportation Planning. Columbus, Ohio: The Ohio State University.

Song, Y., \& Miller, H. J. (2014). Simulating visit probability distributions within planar space-time prisms. International Journal of Geographical Information Science, 28(1), 104-125.

Song, Y., Miller, H. J., Zhou, X., \& Proffitt, D. (2016). Modeling visit probabilities within networktime prisms using Markov techniques. Geographical Analysis, 48(1), 18-42.

Tenkanen, H. (2017). Capturing time in space: Dynamic analysis of accessibility and mobility to support spatial planning with open data and tools. Helsinki: University of Helsinki.

Widener, M. J., Farber, S., Neutens, T., \& Horner, M. (2015). Spatiotemporal accessibility to supermarkets using public transit: An interaction potential approach in Cincinnati, Ohio. Journal of Transport Geography, 42, 72-83.

Winter, S., \& Raubal, M. (2006). Time geography for ad-hoc shared-ride trip planning. Paper presented at the Mobile Data Management, 7th International Conference. doi: 10.1109/MDM.2006.150

Winter, S., \& Yin, Z.-C. (2010). Directed movements in probabilistic time geography. International Journal of Geographical Information Science, 24(9), 1349-1365.

Winter, S., \& Yin, Z.-C. (2011). The elements of probabilistic time geography. GeoInformatica, 15(3), $417-434$. 
Xie, Z., \& Yan, J. (2008). Kernel density estimation of traffic accidents in a network space. Computers, Environment and Urban Systems, 32(5), 396-406.

Yu, H., \& Shaw, S. L. (2008). Exploring potential human activities in physical and virtual spaces: A spatio-temporal GIS approach. International Journal of Geographical Information Science, 22(4), 409-430.

\section{Appendices}

Appendices A and B available as a supplemental file at https://www.jtlu.org/index.php/jtlu/rt/suppFiles/1408/0 